Viso - Cadernos de estética aplicada Revista eletrônica de estética

ISSN 1981-4062

$N^{\circ} 4$, jan-jun/2008

http://www.revistaviso.com.br/
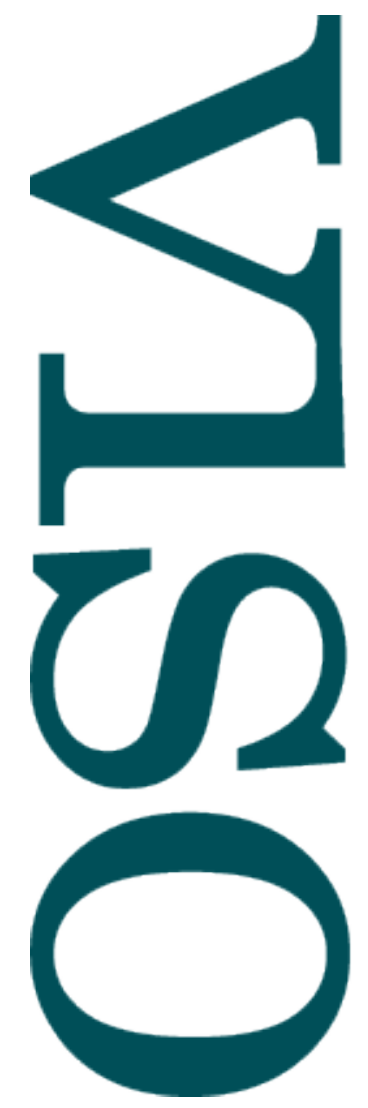

\title{
Herbert Marcuse vai a Paris, Texas Patrick Pessoa
}




\section{RESUMO}

\section{Herbert Marcuse vai a Paris, Texas}

Este ensaio fornece uma interpretação do filme Paris, Texas, de Wim Wenders, à luz da dialética da civilização como apresentada por Herbert Marcuse em Eros e civilização: uma interpretação filosófica do pensamento de Freud. Para que a "aplicação" do pensamento de Marcuse ao filme de Wenders não soterre a obra de arte com filosofemas previamente existentes e de uso disseminado, o contato entre a imagem do cineasta e a palavra do filósofo acontece em uma via de mão dupla. Assim, se a princípio a caracterização marcuseana da dialética entre a pulsão erótica e as demandas da civilização serve para articular algumas das imagens do filme de Wenders, tentamos mostrar, no final de nosso percurso, como o filme de Wenders permite a formulação de algumas questões que tornam visível o quanto o próprio Marcuse negligenciou uma das principais contribuições de Freud para a reflexão estética: a relação essencial entre a pulsão de morte e a negatividade da arte.

Palavras-chave: cinema - psicanálise - Wenders - Marcuse - Freud

\section{ABSTRACT}

\section{Herbert Marcuse visits Paris, Texas}

This essay interprets Wim Wenders' Paris, Texas based on Herbert Marcuse's concept of 'dialectic of civilization' as presented in Eros and Civilization. To prevent that the application of Marcuse's thought to Wenders would arbitrarily read common philosophical notions into the movie, we propose a two-way approach. On the one hand, we employ Marcuse's dialetic between erotic drive and the demands of civilization to articulate some of Wenders' images; on the other hand, we also try to show that his film raises questions that eventually show how Marcuse overlooked one of Freud's main contributions to the aesthetic debate: the essential relationship between the death drive and the negativity of art.

Keywords: cinema - psychoanalysis - Wenders - Marcuse - Freud 
PESSOA, P. "Herbert Marcuse vai a Paris, Texas". In: Viso: Cadernos de estética aplicada, v. II, n. 4 (jan-jun/2008), pp. 95-107.

DOI: $10.22409 / 1981-4062 / v 4 i / 60$

Aprovado: 15.06.2008. Publicado: 30.06.2008.

(C) 2008 Patrick Pessoa. Esse documento é distribuído nos termos da licença Creative Commons Atribuição-NãoComercial 4.0 Internacional (CC-BY-NC), que permite, exceto para fins comerciais, copiar e redistribuir o material em qualquer formato ou meio, bem como remixá-lo, transformá-lo ou criar a partir dele, desde que seja dado o devido crédito e indicada a licença sob a qual ele foi originalmente publicado.

Licença: http://creativecommons.org/licenses/by-nc/4.0/deed.pt_BR

Accepted: 15.06.2008. Publicado: 30.06.2008.

(C) 2008 Patrick Pessoa. This document is distributed under the terms of a Creative Commons Attribution-NonCommercial 4.0 International license (CC-BY-NC) which allows, except for commercial purposes, to copy and redistribute the material in any medium or format and to remix, transform, and build upon the material, provided the original work is properly cited and states its license.

License: http://creativecommons.org/licenses/by-nc/4.0/ 
Em uma entrevista concedida a Laurent Tirard, Wim Wenders esclarece por que "Paris, Texas" (1984) foi um divisor de águas em seu percurso como cineasta:

Para mim, originalmente, tudo o que contava era a imagem. A precisão da imagem, a precisão de uma situação. Nunca a história. Esta noção me era estranha. A rigor, a soma de várias situações podia formar algo que poderíamos chamar de uma história, mas eu absolutamente não acreditava nela como uma proposta com começo, meio e fim. Foi fazendo "Paris, Texas" que eu tive uma espécie de revelação. Compreendi que a história era uma espécie de rio e que se assumíssemos o risco de pôr nosso barquinho ali, e confiássemos no rio, então o barco seria levado para algo mágico. Até então, eu tinha recusado a me deixar levar pelo rio. Eu tinha ficado numa pequena laguna ao lado, porque não tinha confiança. $E$ foi com esse filme que compreendi que as histórias estão aí, que elas existem sem nós. Não há necessidade de criá-las, é a humanidade que as faz existir. Basta apenas deixar-se levar por elas. Desde esse dia, contar algo tornou-se um objetivo cada vez mais forte em minha abordagem do cinema, e o objetivo de fazer belas imagens passou para segundo plano. Por vezes tornou-se até mesmo um obstáculo. No início, o mais belo cumprimento que podiam me fazer era me dizer que eu havia criado belas imagens. Hoje, se me dizem isso, tenho a impressão de ter fracassado. ${ }^{1}$

A princípio, a oposição que Wim Wenders estabelece entre um cinema eminentemente voltado para a criação de "belas imagens" e um cinema basicamente preocupado em "contar uma história" soa excessivamente simplista. Afinal, por mais que uma certa corrente de interpretação da obra de Deleuze insista em opor de modo estanque a imagem-tempo à imagem-movimento, como se ambas fossem mutuamente excludentes, o fato é que a cesura provocada "no decurso do tempo" pelas "belas imagens" de que fala Wenders só é possível como uma ruptura (da compreensão vulgar) do tempo cotidiano - cronológico, homogêneo, sucessivo, tempo cujo modelo em última instância é o espaço, com todas as suas divisões, as suas fronteiras, os seus limites - que o cinema narrativo clássico procura (re)construir na tela. Nesse sentido, a temporalidade intensiva daquelas imagens cuja força não se deixa reduzir à sua função narrativa pressupõe, da parte do espectador, uma expectativa hermenêutica de sentido, da possibilidade de se operarem divisões claras entre o antes e o depois, o passado e o futuro, o mundo subjetivo e o mundo objetivo, o sonho e a realidade, o bem e o mal. Apenas porque, de algum modo, as "belas imagens" de Wenders ou a imagem-tempo de Deleuze jogam com toda essa complexa rede de pressupostos e expectativas dos espectadores é que, ao quebrá-las, tornam-se possíveis o estranhamento e o fascínio que elas despertam. Assim, quando se entrevê a co-dependência mútua entre os dois pólos que ela opõem, torna-se insustentável a dicotomia entre o "cinema da imagem" e o "cinema da história" presente na entrevista de Wenders.

Embora seja insatisfatória para caracterizar tanto "o cinema em geral" - se é que isso existe! - quanto o cinema de Wenders em particular, a dicotomia à qual ele alude tem origem em uma preocupação compreensível, e mesmo louvável. Tratava-se, para o cineasta, de defender a autonomia do cinema face aos interesses colonialistas da literatura e do teatro, que, a despeito das obras de Joyce e de Proust, de Beckett e de lonesco, são muito mais difíceis de libertar do império do sentido (e da narrativa linear) 
do que a imagem cinematográfica, cujo poder de atração remonta ao "prazer da visão" de que fala Aristóteles ${ }^{2}$ ou à pulsão escópica de que fala Lacan ${ }^{3}$ - e que Hitchcock ilustra de forma definitiva em "Janela indiscreta". Tendo em vista a necessidade de defender a especificidade do cinema face a outros modos de expressão artística é que Wenders, em seus filmes da década de 1970, teria se ocupado fundamentalmente com a "precisão da imagem". Uma imagem precisa, segundo essa linha de raciocínio, seria uma imagem liberta de sua instrumentalidade, de sua função narrativa; uma imagem cuja necessidade (ou precisão) não se deixaria medir a partir de (sua serventia a) um outro, mas unicamente a partir de si mesma. Ainda que, em última instância, a soma de várias imagens assim concebidas não excluísse a priori a possibilidade de "formar algo que poderíamos chamar de uma história", isso seria quando muito um ganho secundário, mas de nenhum modo a principal motivação do cineasta. $O$ curioso é que, quando se dá a devida ênfase à possibilidade, e talvez mesmo à inevitabilidade, desse ganho secundário, o depoimento de Wenders ganha uma complexidade de que à primeira vista - quando por exemplo ele afirma que "fazer belas imagens [...] por vezes tornou-se até mesmo um obstáculo" - parecia privado.

Nesse segundo nível de leitura, torna-se visível que, para Wenders, a negatividade das "belas imagens" face à narrativa não a inviabiliza. Apenas a desestabiliza, colocando na berlinda a obsessão do cinema clássico por amarrar todas as pontas de um filme e assim congelar o seu sentido, tornando-o (pretensamente) unívoco. O problema é que, se nos filmes dos anos 1970 "algo que poderíamos chamar de uma história" aparecia em seus filmes mesmo que à revelia do cineasta, o estatuto desse "algo" Ihe permanecia obscuro. Apenas com aquela "espécie de revelação" que Wenders teve enquanto filmava "Paris, Texas" é que finalmente ganhou contornos mais claros a sua própria compreensão do que seria essa "outra história", essa "outra narrativa". Se, segundo uma profissão de fé que Wenders jamais abandonou, a especificidade da imagem cinematográfica tinha a ver com a sua precisão - com o seu rigor e com a sua autonomia -, o correlato dessa precisão da imagem no plano da narrativa só poderia ser uma fidelidade à autonomia das histórias a contar. "As histórias", diz Wenders, "estão aí, elas existem sem nós. Não há necessidade de criá-las, é a humanidade que as faz existir. Basta apenas deixar-se levar por elas." Como quem entra num rio com mil afluentes, o cineasta que se deixa levar pelas histórias que conta assume, de antemão, a perda do controle sobre a sua direção e o seu sentido. Ao entrar nessa "canoinha de nada" ${ }^{4}$, não apenas faz justiça à humanidade, cuja complexidade recusa-se a reduzir aos estereótipos das narrativas convencionais, como sobretudo faz justiça à precisão da imagem. E assim, no Wenders de "Paris, Texas", a própria história se torna imagem. Uma imagem que, não sendo imagem de nada, não sendo representação, não sendo reflexo de qualquer realidade previamente dada, de qualquer mensagem, é capaz de preservar a sua própria força, a sua própria autonomia, a sua própria resistência ao império do sentido, ou, conforme o caso, da mercadoria. 
Essa caracterização do estatuto da articulação entre imagem e narrativa em Wim Wenders, porém, confronta o intérprete, especialmente o intérprete que se propõe a redigir um ensaio de "estética aplicada", com o seguinte problema: se o motor fundamental do cineasta alemão é o imperativo de preservar a autonomia do cinema, seja no plano da elaboração das imagens, seja no plano da construção da narrativa, como é possível interpretar um filme como "Paris, Texas" à luz de Eros e civilização, de Herbert Marcuse, sem simplesmente tratar a obra de Wenders como a ilustração do pensamento marcuseano? Como interpretar a obra de Wenders sem trair a priori a sua profissão de fé como cineasta? Como "aplicar" o pensamento de Marcuse ao filme de Wenders sem destruir impiedosamente aquilo que, nessa obra cinematográfica, resiste aos interesses colonialistas da filosofia?

Essas perguntas - e não a sua resposta! - constituem o pano de fundo deste ensaio, cuja proposta é mostrar de que modo a interpretação marcuseana de Freud é um ponto de partida privilegiado para a compreensão de "Paris, Texas". Para que a "aplicação" do pensamento de Marcuse ao filme de Wenders não soterre a obra de arte com filosofemas previamente existentes e de uso disseminado, é preciso que o contato entre a imagem do cineasta e a palavra do filósofo aconteça em uma via de mão dupla. Assim, se a princípio a caracterização marcuseana da dialética entre a pulsão erótica e as demandas da civilização servirá para articular algumas das imagens do filme de Wenders, tentaremos mostrar, no final deste texto, como o filme de Wenders permite a formulação de algumas questões que tornam visível o quanto o próprio Marcuse negligenciou uma das principais contribuições de Freud para a reflexão estética: a relação essencial entre a pulsão de morte e a negatividade da arte.

\section{Paris X Texas: a dialética da civilização}

Um homem comprou um terreno no deserto. No deserto da pequena cidade de Paris, Texas. Por onde quer que ande, ele traz sempre o deserto - uma foto de seu terreno no deserto - guardado na carteira. Ele perdeu tudo, perdeu mulher e filho, a família e a razão, mas não perdeu a foto de seu pedaço de chão. Esse homem, Travis - nome cuja sonoridade nos remete à idéia de viajante [traveller] -, vivido por Harry Dean Stanton, provavelmente não leu o Zaratustra de Nietzsche. Não sabe que "o deserto cresce: ai daquele que guarda desertos". ${ }^{5}$ Traz o deserto no bolso e no coração. O deserto cresce, torna-se gigantesco: o deserto engole o viajante. Assim começa o filme de Wim Wenders, com Travis passando ao lado da câmera, entrando no coração do deserto e sendo tragado pela sua imensidão.

Pouco a pouco, já que a princípio ele simplesmente não consegue falar, vamos sendo introduzidos à sua história. Já maduro, ele conheceu uma mulher muito mais jovem, por quem se apaixonou perdidamente. No auge da paixão, tudo o que faziam tinha algo de aventuresco, de inusitado, de excitante. Até que o dinheiro acabou e eles se viram premidos pela necessidade de trabalhar para sobreviver. No final do filme, Travis conta 
para Jane, sua ex-mulher, vivida por uma Nastassja Kinski no apogeu da beleza, como Ihe era insuportável ter que sair para trabalhar, deixando-a em casa. A necessidade de, em nome do trabalho e da aceitação social, daquilo que Marcuse chamou de "princípio de desempenho" 6 , ter que renunciar a ficar todo o tempo grudado em sua amante, a obrigação de reprimir o seu Eros em nome das demandas da civilização, era para ele incompreensível e insuportável. Assim, ao contrário do que fazemos os amantes domesticados com nossos amores moralizados, Travis seguidamente abandonava os empregos que conseguia e voltava para a sua amada. Ficava com ela o máximo que podia, isto é, amavam-se até o dinheiro acabar. E aí Travis tinha de arrumar outro emprego, e suportar novas - para ele intermináveis - horas de separação. Essa situação, evidentemente, não tinha como se manter inalterada indefinidamente.

Primeiro, vieram os ciúmes. Será mesmo que a mulher ficava esperando por ele, e apenas por ele, enquanto ele trabalhava? Acossado por essa dúvida, que aponta para a impossibilidade de controlar, e mesmo de conhecer, o desejo do outro, impossibilidade esta que para Travis parecia insuportável, ele começou a beber. Bebendo, tinha como justificar a sua transgressão, aquilo que aos olhos da sociedade pareceria um ciúme doentio. O que a lógica do filme de Wenders nos mostra, porém, é que um tal ciúme não tinha nada de doentio, sendo antes a única reação compatível com a natureza daquela experiência amorosa particular. O ciúme de Travis, como toda a articulação dos símbolos adotados em "Paris, Texas" reafirma, era apenas a conseqüência lógica da experiência da impossibilidade de uma posse absoluta do objeto amoroso, de uma objetificação total da mulher, a dolorosa constatação de que "a relação sexual não existe". Essa constatação era, para um homem como Travis, que não se contentava com nada menos do que tudo, uma mácula que punha tudo a perder. Daí a evasão para o álcool. A despeito de todos os esforços de Jane para demovê-lo daquilo que, também para ela, parecia uma obsessão, Travis só se afundava mais no seu "delírio". Chegava tarde em casa, para provocar ciúmes na mulher. Como, no entanto, isso só a deixava preocupada, mas não enciumada, ele, que identificava ciúme e amor, se sentia ainda pior. E bebia mais.

Uma noite, porém, ela the disse que estava grávida. De três ou quatro meses. Ele, cego de ciúme, sequer percebera. Ainda que o filme não tematize explicitamente a relação entre a gravidez de Jane e as suas reiteradas tentativas de mostrar a Travis o quanto o seu ciúme não tinha qualquer fundamento, é possível enxergar a gravidez de Jane como a segunda saída encontrada pelo casal para escapar às renúncias pulsionais impostas pela civilização - o mundo do trabalho - ao amor - o mundo desse obscuro objeto do desejo. O raciocínio embutido nessa gravidez - e talvez mesmo em qualquer gravidez era a idéia de que o filho seria a corporificação da síntese perfeita entre homem e mulher, a consolidação de uma união plena entre os dois - o renascimento daquele ser andrógino de que fala Aristófanes no Banquete. ${ }^{7}$ Com o nascimento de um filho, teriam raciocinado Jane e Travis, de dois corpos para sempre apartados um do outro se faria apenas um, a unidade ideal, a fusão, o objetivo derradeiro da pulsão erótica. 
O problema é que o nascimento do filho não resolveu nada. Ainda que, com a gravidez de Jane, Travis tenha finalmente se sujeitado aos imperativos do mundo do trabalho, tenha começado a ganhar dinheiro para dar uma "boa vida" para a sua família curiosamente, repita-se, a precondição para sustentar a família é justamente suportar ficar a maior parte do tempo longe dela, coisa que era anteriormente impensável para o mesmo Travis -, o fato é que, com o nascimento do filho, aqueles dois amantes, que ansiavam por se tornar um só ser, ironicamente geraram um terceiro ser. Em vez de fusão, difusão; em vez de aproximação do ideal da plena comunhão, a geração de mais uma barreira.

O resultado é que, se, no primeiro momento que se segue à queda dos amantes no mundo do trabalho, foi Travis quem não suportou a distância e acabou presa de um ciúme obsessivo e, no segundo momento, ambos investiram - mais ou menos conscientemente -na gravidez como possibilidade de uma comunhão irrestrita, um ser que faria de Travis e Jane uma unidade perfeita, nesse terceiro momento é Jane quem não suporta a dupla sujeição de ser mãe. Como não se sentir sufocada diante daquelas expectativas sociais que exigem da mãe que seja não apenas a mantenedora ideal de uma criatura tão frágil, mas ao mesmo tempo a mulher purificada da fatalidade da pulsão sexual?

Depois do nascimento do filho, Jane passa a ficar irritada com tudo, como se a própria existência do bebê fosse uma injustiça. Travis se esforça para agradá-la, compra presentes para ela, a leva para jantar fora com freqüência. Mas nada parece satisfazê-la. Depois de dois anos, ele finamente se dá conta de que as coisas jamais poderiam voltar a ser como antes - sem se dar conta, talvez, do quanto este "antes" é ambíguo. Desesperado, ele volta a beber, mas agora, quando chega tarde em casa, Jane não sente nem ciúmes nem preocupação, mas apenas raiva. Ela o acusa de mantê-la em cativeiro, de tê-la seqüestrado apenas para engravidá-la, em uma síntese tão poética quanto realista de um dos aspectos da experiência da maternidade - sem dúvida o aspecto menos difundido socialmente... Jane diz então a Travis que tem sonhos recorrentes de que está fugindo, correndo nua pelos campos e pelas estradas, sempre correndo, até que, não se sabe de onde, ele aparece e impede a sua libertação. Para fazer face a esse sonho de Jane - ou quem sabe realizá-lo - Travis passa a amarrá-la à cama com um cow belt, uma daquelas coleiras com um sininho comumente encontráveis nos pescoços das vacas.

Mas nem mesmo as correntes com as quais Travis a prendia ao pé da cama, reais na simbologia do filme, mas existentes imaginariamente na casa de qualquer família burguesa, conseguiram detê-la. O seu desejo colocou fogo na casa - em imagem que posteriormente seria retomada por David Lynch em $A$ estrada perdida- e ela fugiu. Abandonou o filho na casa do cunhado (Dean Stockwell) - homem inteiramente sujeitado à civilização, que não por acaso trabalhava compulsivamente e acabara de comprar uma majestosa casa perto do aeroporto, isto é, perto da fuga eternamente adiada - e foi 
novamente em busca do apelo da vida, de Eros, daquela mesma intensidade vital que julgara ter encontrado nos primórdios da relação com Travis.

Como ficamos sabendo apenas na última cena do filme, aquela que indiscutivelmente garante o seu lugar entre as obras-primas da história do cinema, a fuga de Jane acaba por conduzi-la a um prostíbulo, onde, mais do que vender o seu corpo, ela vende a sua imagem. $O$ fato de que ela passa os seus dias satisfazendo as fantasias eróticas dos clientes do lugar, sem jamais ter um contato direto com as mãos deles, mas apenas com a sua própria imagem especular - os clientes ficam atrás de um espelho falso, de modo que podem vê-la e comandar as suas ações através de um microfone, sem que ela possa vê-los, e veja apenas a sua própria imagem no espelho -, aponta para a trágica sabedoria encarnada pelo filme: a de que a plenitude prometida pelas imagens fantasmáticas - sejam as da propaganda, do cinema ou de nossos próprios sonhos são um mero jogo de cena que esconde o dado inevitável da finitude, o dado real da castração. A profissão de Jane é uma confissão: alimentando as fantasias dos outros, renunciou às suas próprias, e, como confessa a Travis quando ele finalmente a encontra no paraíso grotescamente artificial que passou a habitar, apenas um derradeiro estímulo (ou fantasia) impulsionava as suas performances: finalmente poder realizar plenamente as fantasias de Travis. "Eu acho que todos os homens que vêm aqui", ela the diz, "são você, Travis."

Com a fuga de Jane, como ficamos sabendo ao longo do filme, o mundo de Travis desmorona, ele é engolido pelo deserto. Apenas uma miragem o acalenta: encontrar as suas raízes, retornar a Paris, Texas, lugar em que, como saberemos mais tarde, seu pai e sua mãe teriam feito sexo pela primeira vez. Paris, Texas, portanto, é, na fantasia de Travis, o lugar onde ele teria sido gerado - e para o qual cumpria retornar. Essa informação funciona como uma possível chave para a compreensão do sentido do filme, aquilo que nos permite amarrar algumas de suas pontas.

O Travis do começo do filme, o viajante desnorteado, é o homem que, desesperado pela perda de Jane, o sentido de seus dias, precisa recuperar o seu prumo, o seu princípio [arché], isto é, a sua direção. E que, não sem ressonâncias obviamente edípicas, buscará (construir) esse princípio recorrendo justamente ao momento anterior à sua queda na vida, no mundo (do trabalho), na experiência da dor de renunciar à plenitude paradisíaca que associa à sua estadia no útero materno, correlato mundano dos paraísos extra-mundanos almejados pelos religiosos. O Travis do começo do filme, em suma, é alguém que, não tendo suportado a castração do próprio desejo, o terrível caminhar sobre o fio da navalha entre Eros e a vida civilizada, sucumbe à miragem da própria ilimitação, da ausência de horizonte e de limite que caracteriza o deserto como filmado por Wenders.

O filme, felizmente, não se constrói como um flash-back simples, que, uma vez tendo explicado por que Travis está na situação em que se encontra nas primeiras tomadas, simplesmente termina. O término do filme não se esgota em seu início, já que o drama é 
desencadeado por um acontecimento que amplia o jogo de oposições esboçado até aqui: "o irmão civilizado", satisfeito com a própria castração e as compensações oferecidas pela cultura, irmão este que não por acaso é casado com uma parisiense uma francesa (Aurore Clément) que fala inglês com um forte sotaque, como a indicar o seu não-pertencimento àquela civilização ainda um tanto quanto bárbara -, o irmão que pegou o filho de Travis e Jane para criar quando ambos entregaram-se, cada um a seu modo, a seus próprios desejos, esse irmão, que julgava que Travis (e o apelo por ele representado) estavam mortos, vai buscá-lo no coração das trevas, no meio do deserto, da barbárie do desejo não reprimido e domesticado.

Walt (Dean Stockwell), depois de suportar a dificuldade de Travis em falar, em elaborar as sufocantes causas de sua angústia - Travis só falará, como se estivesse diante de um psicanalista, de costas para a imagem fantasmática de Jane, no final do filme, na emblemática cena do peep show - leva-o de volta para sua casa em Los Angeles, no próprio coração do mundo dito civilizado. Nesta casa, Travis reencontrará Hunter (Hunter Carson), seu filho com Jane, então com dez anos, mas que ele não via há seis ou sete. O reencontro de ambos é construído com uma pungente delicadeza. A princípio, o menino resiste ao pai, que não se enquadra naquele mundo administrado em que os tios o haviam criado. Mas, à medida que ambos vão convivendo, a ternura do pai, sua simplicidade, sua resistência muda aos padrões morais ditos civilizados, vão progressivamente conquistando o menino, que percebe que a vida poderia ser muito mais livre, mais criativa, interessante, inaudita, inesperada, do que prometiam os seus tios. Essa percepção é sintetizada pela cena em que ambos voltam juntos da escola de Hunter, mais próximos e parecidos do que nunca, entregues ao mágico prazer de se imitarem, apesar de permanecerem de lados distintos da rua. Confrontado com a possibilidade de seguir os incertos passos do pai na busca pelo ainda mais incerto paradeiro da mãe, Hunter não hesita. Troca, inclusive com uma certa brutalidade (ou ingratidão), a segurança do civilizadíssimo lar dos tios por uma aventura com aquele pai recém reconhecido.

No final do filme, Hunter acaba reencontrando, por meio do sacrifício paterno, o útero materno, a "Paris, Texas" que seu pai em vão procurara. Hunter fica com Jane. Travis, por sua vez, depois de assegurar-se do reencontro da mãe com o filho, vai embora. O espectador, ainda extasiado diante de uma história com tamanha força, se pergunta por que, se não havia qualquer obstáculo externo, pai, mãe e filho não puderam ficar juntos, não puderam ser felizes para sempre... O filme não responde de maneira unívoca a essa pergunta, mas apenas indica, nas palavras gravadas que Travis lega ao filho, que the seria impossível não repetir novamente os caminhos que o haviam levado ao desastre. Por que, para Travis, seria impossível escapar a isso que ele sente como um circuito fechado? O que haveria nessa "compulsão à repetição"?

Com essa pergunta, o filme silencia. 


\section{Epílogo: Marcuse à luz de Wenders}

O decisivo na leitura que Marcuse faz de Freud é a concepção de que, se "o princípio do prazer tem a tarefa de libertar inteiramente o aparelho mental da excitação" ${ }^{8}$ e se a pulsão de morte, que se revela fenomenologicamente na compulsão à repetição de determinados processos mentais, tem a ver com "o esforço superlativamente universal de toda a substância viva, ou seja, regressar à imobilidade, à quietude, do mundo inorgânico", então "a sexualidade obedece, fundamentalmente, ao mesmo princípio que a pulsão de morte". ${ }^{10} \mathrm{O}$ problema é que, ao definir a pulsão de morte como aquilo que visa simplesmente a eliminar toda e qualquer tensão, Marcuse acaba por subsumi-la à pulsão erótica e ao princípio do prazer, negligenciando a sua especificidade.

Segundo Vladimir Safatle, cujo texto "Marcuse e as metamorfoses da pulsão" foi a inspiração decisiva para este epílogo, tal esvaziamento da negação como elemento constitutivo da realidade exigiu a formulação de um mito: o da simbiose absoluta com a mãe, que permitiria uma relação com o outro que não fosse uma relação de dominação. "O raciocínio de Marcuse é simples: se o princípio de realidade fundado na repressão pulsional está vinculado inicialmente à internalização da Lei paternal e seus princípios simbólicos de organização, então no interior do fluxo libidinal simbiótico entre bebê e mãe poderíamos encontrar os vestígios de um outro modo de acesso à realidade." 11 Esse outro modo de acesso à realidade, esse verdadeiro paraíso perdido seria o fundamento da promessa de uma civilização não-repressiva, idéia que responde pela celebridade de Marcuse na década de 1960.

O que Marcuse não teria percebido é que a centralidade da pulsão de morte na obra de Freud deve-se menos à idéia de uma compulsão à destruição do que à percepção das reiteradas irrupções de algo que não se deixa simbolizar. Escreve Safatle:

Operando também através da recuperação filosófica da teoria pulsional freudiana, Adorno chega a uma conclusão oposta [à de Marcuse]. Ao falar sobre esta atitude de integral identificação com o meio, Adorno insiste não na integração harmônica e totalizadora, mas na "tendência a perder-se no meio ambiente [Umwelt] ao invés de desempenhar aí um papel ativo, da propensão a se deixar levar, a regredir à natureza. Freud denominou-a pulsão de morte [Todestrieb], Caillois le mimetisme" (ADORNO e HORKHEIMER, Dialética do esclarecimento, p. 212). ${ }^{12}$

Essa irresistível atração pelo silêncio, pela "natureza compreendida como espaço do inorgânico, figura maior da opacidade material aos processos de reflexão", ${ }^{13}$ parece ser, em última instância, o que impede o fim da errância de Travis, a sua volta ao lar, a uma identidade constituída e passível de inscrição simbólica. Por isso, poder-se-ia especular, tão logo deixa Hunter nas mãos de Jane, é inevitável que ele novamente se perca no meio ambiente, se deixe regredir à natureza, não resista ao apelo do deserto. E assim, talvez, a imagem que abre o filme, com Travis passando ao lado da câmera, entrando no coração do deserto e sendo tragado pela sua imensidão, possa também ser entendida como a imagem com que o filme se encerra. 
"O silêncio daquela região era igual ao do sepulcro: dissera-se que a vida das coisas ficara estúpida diante do homem." ${ }^{14} \mathrm{E}$, não obstante, é da escuta desse silêncio que o intérprete precisa arrancar - nem que para isso precise usar de violência - a sua voz. Pelo menos é isso que a precisão das belas imagens de Wim Wenders parece ensinar ao talvez excessivamente loquaz e esquemático Herbert Marcuse...

\footnotetext{
* Patrick Pessoa é doutor em filosofia pela UFRJ/PPGF.

${ }^{1}$ TIRARD, L. Grandes diretores de cinema. Rio de Janeiro: Nova Fronteira, 2006, p. 118.

${ }^{2}$ ARISTÓTELES. Metafísica, Livro I (980a): "Todos os homens têm, por natureza, o desejo de conhecer. Uma prova disso é o prazer das sensações, pois, independentemente de sua utilidade, elas nos agradam por si mesmas e, mais do que todas, as sensações visuais."
}

${ }^{3}$ LACAN, Jacques. Os quatro conceitos fundamentais da psicanálise. Rio de Janeiro: Zahar, 1985, p. $171 \mathrm{ff}$.

${ }^{4}$ GUIMARÃES ROSA, J. "A terceira margem do rio". Em: Primeiras histórias. Rio de Janeiro: José Olympio, 1976, p. 32: "Sou homem, depois desse falimento? Sou o que não foi, o que vai ficar calado. Sei que agora é tarde, e temo abreviar com a vida, nos rasos do mundo. Mas, então, ao menos, que, no artigo da morte, peguem em mim, e me depositem também numa canoinha de nada, nessa água, que não pára, de longas beiras: e, eu, rio abaixo, rio a fora, rio a dentro-o rio."

${ }^{5}$ NIETZSCHE, F. Assim falou Zaratustra. Rio de Janeiro: 1989, p. 306.

${ }^{6}$ MARCUSE, H. Eros e Civilização: uma interpretação filosófica do pensamento de Freud. Rio de Janeiro: Zahar, 1968, p. 51-60. Para Marcuse, "o princípio de desempenho é a forma histórica predominante do princípio de realidade. No princípio de realidade está subentendido o fato fundamental de Ananke ou carência [Lebensnot], o que significa que a luta pela existência tem lugar num mundo demasiado pobre para a satisfação das necessidades humanas sem restrição, renúncia e dilação constantes. Por outras palavras, qualquer satisfação que seja possível necessita de trabalho [...]. Enquanto o trabalho dura, o que ocupa praticamente toda a existência do indivíduo amadurecido, o prazer é suspenso e o sofrimento físico prevalece. E como os instintos básicos lutam pelo predomínio do prazer e a ausência de dor, o princípio de prazer é incompatível com a realidade, e os instintos têm de sofrer uma arregimentação repressiva." O desconcerto de que parte Marcuse em sua análise da civilização moderna tem a ver com o progresso tecnológico, que, se a princípio deveria liberar o homem do excesso de trabalho e assim diminuir os mecanismos repressivos da civilização, na prática exige renúncias pulsionais cada vez maiores e dissemina uma mais-repressão incompatível com o nosso estágio técnico de desenvolvimento.

7 PLATÃO. "O Banquete". Em: Diálogos. Trad. Jaime Bruna. São Paulo: Cultrix, 1995, p. 59: "ARISTÓFANES: É mister começardes por aprender o que é a natureza humana e as mudanças por que passou. Outrora, realmente, nossa constituição não era a mesma de hoje, mas diferente. Em primeiro lugar, os sexos da espécie humana eram três, não dois como hoje, masculino e feminino; havia ainda um terceiro, que participava de ambos aqueles; o nome conservou-se até hoje, embora o sexo mesmo tenha desaparecido; existia, naquele tempo, um que era o andrógino; participava, assim, no aspecto como no nome, de ambos os sexos, macho e fêmea; hoje não existe senão como nome insultuoso. Em segundo lugar, a figura de cada homem estava inteira [...]."

${ }^{8}$ FREUD, S. apud MARCUSE, H. Op. cit., p. 43.

${ }^{9}$ FREUD, S. apud MARCUSE, H. Op. cit., p. 44. 
${ }^{10}$ MARCUSE, H. Op. cit., p. 45.

${ }^{11}$ SAFATLE, V. "Marcuse e as metamorfoses da pulsão". Em: Herbert Marcuse: Dimensão Estética - Homenagem aos 50 anos de 'Eros e Civilização'. Belo Horizonte: ABRE, 2006, pp. 4-5.

12 Ibidem, p. 6.

13 Ibidem.

${ }^{14}$ MACHADO DE ASSIS, J. M. Memórias póstumas de Brás Cubas. São Paulo: Abril, capítulo VII. 